\title{
Los mexicanos en Montreal: ¿Una comunidad transnacional?
}

\section{Mexicans in Montreal: a transnational community?}

\author{
JUAN Luis KLEIN* \\ Mauricio Aranzazu**
}

\begin{abstract}
This article analyses the ties Mexican immigrants in Montreal develop with the host society and those they keep with their communities of origin. From the transnational perspective, the analysis is based on data obtained from documents and interviews with Mexican entrepreneurs, professionals and refugees living in Montreal. The analysis concludes that Mexican immigrants in Montreal live their territorial identity in a situation of social and economic stress characterized by a hybrid sense of belonging. "We do not feel neither from here nor from there", say the majority of interviewees; which appears to the authors as a sign of a transnational community in construction.
\end{abstract}

Keywords: mexicans, transnational space, migrant, sense of belonging, identity.

\begin{abstract}
Resumen
Este artículo analiza los lazos que los inmigrantes mexicanos en Montreal mantienen con la sociedad de acogida y con sus comunidades de origen. Nos basamos en el estudio de documentos y en la realización de entrevistas con empresarios, profesionales y refugiados mexicanos residentes en Montreal. Concluimos que los mexicanos residentes en Montreal viven su identidad territorial en una situación de tensión social y económica donde domina un sentimiento de pertenencia híbrida. "No nos sentimos ni de aquí, ni de allá" nos confía la mayoría de los entrevistados, lo cual da muestras de una comunidad transnacional en gestación.
\end{abstract}

Palabras clave: mexicanos, espacio transnacional, migrante, sentimiento de pertenencia, identidad.

* Departamento de geografía, Universidad de Quebec en Montreal, correo-e: klein.juan-luis@ uqam.ca

** Dirección General de Ordenamiento Ambiental Territorial. Ministerio de Ambiente y Desarrollo Sostenible-Colombia, correo-e:mauricioaranzazuospina@gmail.com 


\section{Introducción}

Este texto resume un trabajo sobre las prácticas sociales, económicas y de identidad de los mexicanos instalados en Montreal, y sobre los lazos que ellos mantienen con sus comunidades de origen. Se imbrica en el marco de un proyecto global acerca de las migraciones mexicanas y la pertenencia de los migrantes a comunidades transnacionales llevado a cabo por un grupo de investigadores en México, Estados Unidos y Canadá.

Este proyecto plantea la hipótesis general de que la inscripción de los migrantes en una comunidad transnacional tiene efectos sobre su capacidad empresarial, en la medida que este tipo de comunidad les proporciona el capital social necesario para llevar a cabo emprendimientos económicos. La hipótesis se basa en observaciones previas realizadas en Estados Unidos, donde el movimiento de mexicanos, a través de la frontera norte de su país y sus interrelaciones con sus comunidades de origen, tiene raíces históricas.

Habida cuenta que el flujo de inmigrantes mexicanos a Canadá es reciente y no es comparable en volumen con el flujo que se dirige a los Estados Unidos, nos ha parecido necesario verificar la pertinencia, en este caso, del concepto de comunidad transnacional. Para ello, hemos tomado el caso de los inmigrantes mexicanos concentrados en la Región Metropolitana de Montreal. La elección de este caso se justifica porque, según el censo canadiense realizado en $2011^{1}$, viven en Canadá 86,175 personas nacidas en México, de las cuales 20,465 residen en la provincia de Quebec. Montreal concentra a 17,630, es decir, 86,2\% del total provincial y $20,5 \%$ del total canadiense. Estos mismos datos censales establecen que Montreal es la metrópolis canadiense con mayor concentración de residentes nacidos en México (Statistique Canada, 2011).

El texto se ha estructurado de la manera siguiente: en primer lugar, nos referimos de manera específica a la idea de transnacionalismo y al concepto de comunidad transnacional. También abordamos el uso de este concepto en el marco de los estudios sobre la emigración y, en particular, sobre la emigración mexicana. En segundo lugar, presentamos el marco metodológico de nuestra investigación sobre los inmigrantes mexicanos en Montreal, así como los conceptos operativos en ella movilizados, es decir, los conceptos de espacio, redes e identidad. También presentamos los pasos y etapas de la investigación empírica. En un tercer apartado damos a conocer los resultados de la investigación y abordamos el perfil histórico y social de la comunidad mexicana en Montreal, las redes en las

${ }^{1}$ Ultimo disponible en el momento en que se realizó la investigación. Los datos del censo realizado en el 2016 aún no han sido tratados. 
cuales se insertan los inmigrantes mexicanos y el desarrollo de lo que denominamos identidad híbrida; para hacerlo, nos servimos de algunos indicadores importantes considerados por el enfoque teórico del transnacionalismo. Los resultados presentados en el tercer apartado deben ser vistos e interpretados como referentes que servirán para identificar si la comunidad mexicana de Montreal constituye una comunidad transnacional, eje central de este texto, y no como una caracterización socioeconómica exhaustiva de estos inmigrantes. En la conclusión, veremos que el uso del concepto de comunidad transnacional es prematuro en el caso de los inmigrantes mexicanos en Canadá, lo que no significa que no haya algunos embriones de transnacionalismo en su seno. Y también concluiremos que a pesar de ello, los inmigrantes mexicanos demuestran una fuerte capacidad de emprendimiento.

\section{Comunidades transnacionales y movimiento migratorio México- Montreal}

El estudio de la migración internacional, vista desde las prácticas culturales de los migrantes y desde las relaciones que estos mantienen con sus lugares de origen y destino, ha motivado un sinnúmero de investigaciones - principalmente a partir de la década de los noventa - inscritas en los campos teóricos del transnacionalismo y de la transnacionalidad. Algunos autores establecen la diferencia entre ambos términos, haciendo uso del primero para referirse a relaciones de identidad y pertenencia entre los migrantes y reservando el segundo a las prácticas sociales y a las transacciones transfronterizas que estos llevan a cabo (Faist, 2013; Moctezuma, 2008).

Para efectos del presente texto, haremos uso del campo teórico del transnacionalismo refiriéndonos por extensión a las prácticas culturales desarrolladas por los inmigrantes mexicanos en Montreal, las cuales abarcan los ámbitos social, económico, político y de identidad.

El transnacionalismo es un fenómeno intensificado en los últimos años debido a los procesos de globalización y de mundialización, así como a la revolución de la tecnología de los medios de comunicación (Castells, 2001; Faist, 2013); factores que han favorecido la expansión de las redes y el sostenimiento de las mismas de manera flexible (Narváez-Gutiérrez, 2007). El transnacionalismo considera las regiones periféricas y centrales como espacios que forman parte de un mismo sistema económico global, rompiendo así con la perspectiva de las regiones ganadoras y perdedoras planteada en los ańos noventa por Benko y Lipietz (1992) en un intento de renovación de la geografía económica. En el transnacionalismo, las 
nociones de frontera, comunidad, tejido social e identidad son reconsideradas en función de los procesos de desplazamiento de los migrantes.

\subsection{La noción de transnacionalismo}

Los autores del transnacionalismo hacen frecuentemente referencia en sus trabajos a la definición formulada en 1992 por Glick-Schiller, Basch y Blanc-Szanton, quienes lo definen como:

[...] un proceso social en cual los migrantes establecen espacios sociales en los cuales se cruzan fronteras geográficas, culturales y políticas. Los inmigrantes son vistos como transmigrantes cuando desarrollan y conservan relaciones múltiples familiares, económicas, sociales, organizacionales, religiosas y políticas que atraviesan las fronteras. Un elemento esencial de transnacionalismo es la multiplicidad de actividades en las cuales los inmigrantes (transmigrantes) participan, tanto en el país de acogida como en el de origen (Glick-Schiller et al., 1992: 9) (traducción del inglés).

Las actividades a las cuales se refiere esta definición se agrupan de acuerdo con el tipo de prácticas y de actores implicados. Según el tipo de prácticas, estas pueden ser económicas, políticas y socioculturales, y según los actores implicados, pueden ser de "alto nivel" cuando son desarrolladas por los Estados y corporaciones multinacionales, y de "bajo nivel", cuando son desarrolladas por los inmigrantes y sus compatriotas en su país de origen (Smith y Guarnizo, 1998; Blanco, 2007). Estas últimas prácticas, las de bajo nivel, son las que más interesan a los fines de este estudio, pues son llevadas a cabo en la base por los inmigrantes mismos en su calidad de "ciudadanos" de un espacio transnacional.

Entre las actividades económicas de este tipo encontramos los emprendimientos realizados por los inmigrantes como mecanismos de subsistencia y el envío de remesas a sus familias. Existen, además, empresas creadas por los inmigrantes dedicadas a la importación y exportación de bienes y servicios hacia y desde sus países de origen. Estas empresas se convierten en transnacionales en la medida en que contribuyen al desarrollo local de sus comunidades de origen.

A este mismo nivel, el transnacionalismo político se relaciona con la financiación de campañas electorales en el país de origen, la participación en procesos políticos electorales, ya sea como elector o como candidato, y la creación de diferentes comités en el territorio de acogida, siempre con la perspectiva del mejoramiento de las condiciones de vida de las comunidades de origen. Con respecto a las actividades sociales e identitarias, éstas se refieren al fortalecimiento de la solidaridad entre los grupos de inmigrados, al sostenimiento a lo largo del tiempo de las relaciones so- 
ciales y familiares con sus compatriotas en el lugar de origen, y a aquéllas encaminadas a la conservación de la identidad cultural de los inmigrantes en el lugar de acogida (Portes, et al., 1999; Portes, 2004).

\subsection{La noción de comunidad transnacional}

Las comunidades transnacionales corresponden a las nuevas formas de comunidad establecidas por los migrantes en el contexto de la mundialización y de la globalización. Su característica principal reside en la hibridación de sentimientos de pertenencia y de identidad (Martinielo, 2007). Se trata de comunidades compuestas por individuos o por grupos establecidas en el seno de diferentes sociedades nacionales, que actúan a partir del interés y de referencias comunes (territoriales, religiosas, lingüísticas) y que se apoyan en redes sociales para fortalecer su solidaridad, más allá de las fronteras nacionales (Kastoryano, 2000: 353, citada por Bruneau, 2009).

Estos grupos se estructuran gracias a la acción de intermediarios que actúan en función de intereses específicos (Rottenbenger-Kwok, 2007)². Las comunidades transnacionales se inscriben tanto en la cultura del país de origen como en la sociedad de acogida, dando lugar al surgimiento de espacios plurilocales (Canales y Zlolniski, 2001; Enríquez, 2000; Roldán, 2009). En ese sentido, las comunidades transnacionales constituyen el marco donde las prácticas transnacionales se consideran como medio de vida (Cabezas, 2012).

\subsection{El espacio transnacional}

Los espacios transnacionales engloban a grupos de personas residentes en países diferentes unidas por intereses y referencias culturales comunes y que se apoyan en redes transnacionales (Kastoryano, 2000; Bruneau, 2004). Los espacios trasnacionales dan lugar a una nueva concepción de territorio como resultado de la dualidad entre lugar de partida y lugar de acogida de migrantes, lugares dentro los cuales se inscriben diversos espacios locales (Canales y Zlolniski, 2001; Enríquez, 2000; Roldán, 2009).

La multiplicación en el mundo de estos espacios transnacionales constituye un signo de la restructuración del espacio global, la cual está ligada a la mundialización. En este contexto, los territorios de los estados nacionales delimitados según los principios westfalianos ya no tienen el monopolio de la estructuración espacial del mundo, cohabitan con di-

\footnotetext{
${ }^{2}$ A este respecto, es interesante consultar el caso de la comunidad transnacional de origen chino establecida en Brossard, un municipio situado en la periferia de Montreal, donde los intermediarios son agentes inmobiliarios (Lambert, 2015).
} 
versas manifestaciones espaciales como las redes y las regiones virtuales (Badie, 1995; Castells, 2004), y las diversas formas de metropolización y de fragmentación a nivel infranacional (Swyngedouw, 1997; HiernauxNicolas, 1999; Klein, 2005; Klein 2016)

En ciertos casos, los espacios nacionales son transfronterizos como es el caso del espacio estructurado por los inmigrantes mexicanos a través de la frontera con los Estados Unidos. Ellos hacen una reconstrucción de su comunidad más allá de las fronteras (Garduño, 2003). Este tipo de espacios transnacionales mantienen una cierta contigüidad. En otros casos, se trata de espacios sin continuidad territorial, estructurados por individuos o grupos cuyos referentes son lejanos; inmigrantes que mantienen lazos y relaciones con sus parientes y amigos, quienes permanecen en el lugar de origen. Este es el caso de los inmigrantes mexicanos en Montreal (Aranzazu, 2013) o de los trabajadores mexicanos que participan en programas de empleo temporal en regiones rurales de la provincia de Quebec (Falciglia, 2013).

En este texto abordaremos de manera específica el caso de los inmigrantes mexicanos en Montreal, los cuales se inscriben en un espacio transnacional sin continuidad. Este espacio depende, más que de proximidad física, de lazos sociales, de interrelaciones y de redes. En este caso, la constitución de redes sociales es fundamental. Al llegar los inmigrantes a un nuevo territorio, en la mayoría de los casos, no cuentan con el capital social aportado por la pertenencia a redes sociales fuertes. Para mitigar esta debilidad, se insertan en las redes sociales locales establecidas por los inmigrantes en el país de acogida, y construyen redes con la colectividad de origen, lo que con frecuencia, a su vez, se traduce en actividades en favor del desarrollo local de su comunidad de origen (Faret, 2003), aunque también en tensiones y conflictos (Canales y Zlolniski; 2001) puesto que la comunidad de origen no queda estática mientras que la construcción mental que el inmigrante hace de ella tiende a serlo.

\subsection{Los espacios transnacionales y las migraciones mexicanas}

Los espacios trasnacionales, producidos por las comunidades mexicanas trasnacionales, ocupan un lugar importante en la investigación sobre el tema de la migración. En gran parte, estas investigaciones han estudiado las migraciones hacia los Estados Unidos (Smith y Guarnizo, 1998; Moctezuma, 2002; Faret, 2003; Garduño, 2003). Se concluye de estos trabajos que las comunidades de inmigrantes mexicanos muestran una alta capacidad de asociación en el lugar de acogida y realizan un aporte al desarrollo local de sus comunidades en las municipalidades de las que provienen. 
Varios miles de iniciativas económicas generadas desde los comienzos de la década del 2000 dan muestras de una fuerte capacidad de emprendimiento y de relaciones solidarias, las cuales se traducen en envíos colectivos de fondos hacia sus comunidades en las localidades de origen (Roldan, 2009). Entre las iniciativas más comunes se encuentran los clubes de inmigrantes, las cooperativas, los micro-bancos locales y la inversión en maquiladoras. Entre las más recientes está la iniciativa Construmex, que tiene por objetivo la mejora de las casas de los inmigrantes, la construcción o la compra de una casa en México, por ellos o por sus familias de escasos ingresos (García de la Torre, 2011). De esta manera, los inmigrantes cuentan con redes sociales ya constituidas, caracterizadas por una identidad cultural fuerte (Canales y Zlonlniski, 2001; Delgado y Mañán, 2005), redes que, por lo demás, refuerzan los circuitos migratorios.

Con respecto a la migración mexicana en Canadá, sin embargo, existen estudios insuficientes y se sabe muy poco acerca de las relaciones entre los inmigrantes y sus comunidades en los lugares de origen. Esto se explica por el hecho de ser una migración reciente, así se haya intensificado a partir del año 2000. Esta es la razón por la cual decidimos hacer una investigación sobre la migración mexicana en Canadá y la eventual construcción de un espacio transnacional.

\section{Marco metodológico}

La investigación que ha permitido redactar este texto ha sido de naturaleza exploratoria e inductiva. A partir del enfoque del transnacionalismo construimos un marco metodológico (conceptos operativos, variables e indicadores) que nos permitió verificar la pertinencia de la noción de comunidad transnacional para abordar el caso de los inmigrantes mexicanos en Montreal. En esta sección presentaremos dicho marco metodológico. Primero, nos referiremos a los conceptos operativos que permitieron la interpretación de los datos empíricos. En segundo lugar abordaremos los pasos seguidos en la obtención y en el tratamiento de estos datos.

\subsection{Los conceptos operativos: espacio, red e identidad}

Nuestro abordaje del transnacionalismo se realiza desde una perspectiva geográfica, la cual está basada en una concepción social del espacio (Klein, 1997). Según esta visión, el espacio es el producto de actores sociales, quienes a través de relaciones convergentes y conflictuales delimitan y configuran territorios y territorialidades en los cuales se despliegan y se desarrollan 
modalidades de regulación, instancias de gobernanza, relaciones sociales y sentimientos de pertenencia y de identidad (Klein, 2005; 2006).

En la sociedad moderna, sobre todo en la posguerra, la forma espacial de referencia en la estructuración geopolítica, geoeconómica y social del mundo fue el territorio nacional, definido en términos de Estado-Nación (Badie, 1995; Sassen, 2007; Klein, 2016). A partir de los años treinta, el Estado-Nación estuvo íntimamente ligado a la regulación fordista, a la gobernanza de inspiración keynesiana centralizada en el estado, a relaciones sociales centradas en las instituciones nacionales y a diferentes declinaciones de la identidad nacional. La gestión económica y la gestión social se desarrollaban en el marco del territorio nacional, lo que establecía une cohesión social fuerte, así como la adhesión a valores nacionales comunes, y una cohesión territorial, también fuerte, en la cual las diferentes delimitaciones infranacionales (barrio, municipio, región, nación) se imbricaban.

La cohesión interna era producida por diversos procesos, entre los cuales figuraban la educación y el mercado del trabajo, lo que generaba una sociedad más o menos homogénea en términos culturales, en la cual diversas formas de protección aseguraban la integración socioeconómica de los inmigrantes. El proteccionismo mexicano hasta los años ochenta, el melting pot en Estados Unidos y la "revolución tranquila" que se llevó a cabo en la provincia de Quebec (Canadá), a partir de 1960, son ejemplos de procesos de estructuración de este tipo de espacio.

La globalización y la mundialización anulan la eficiencia de las instituciones que favorecían la estructuración del espacio nacional como marco exclusivo de regulación (Sassen, 2007). La apertura de las fronteras impuestas por las diversas formas de desreglamentación asociadas a la globalización, las cotemporalidades generadas en espacios discontinuos y virtuales por las nuevas tecnologías de comunicación, las reestructuraciones del mercado del trabajo a escala nacional e internacional, la movilidad de los factores de la producción (capital y trabajo), entre otros aspectos, hacen que el Estado-Nación cohabite y en algunos casos se vea sobrepasado por otras configuraciones espaciales que actúan como generadores de cohesión y de identidad. Estas configuraciones abarcan lo local y lo global (Klein, 2014). Es en este marco conceptual en el que situamos la idea del espacio transnacional.

La armadura social de los espacios transnacionales la constituyen las redes transnacionales, es decir, redes creadas por grupos o individuos que traspasan el ámbito nacional. Estas redes conectan espacios distantes bien diferenciados y están sujetos a la evolución de los medios de comunicación (Lacroix, 2003; Huang, 2013; Pedraza y Cortés, 2012). Las redes le atribuyen a la migración un carácter social y colectivo que permite mantener 
lazos entre grupos de personas de la misma o de diferente composición étnica (Ávila-Molero, 2015), familias, amigos, vecinos, etc. Asimismo, en el espacio de acogida, las redes que los inmigrantes tejen con inmigrantes del mismo origen y con inmigrantes de origen diferente aumentan su capital social (Narváez-Gutiérrez, 2007).

En sus inicios, la noción de redes sociales fue utilizada en relación con la reciprocidad, el intercambio de mercancías y los servicios de información. Con el surgimiento del concepto de transnacionalismo, esos aspectos han sido vistos como componentes de la comunicación que transfieren signos, símbolos, información y valores de los grupos de inmigrantes (Canales y Zlolniski, 2001; Garduño, 2003). La duración y la intensidad de estas redes están directamente relacionadas con la estructuración de espacios transnacionales. Las redes de larga duración y fuerte intensidad dan lugar a comunidades transnacionales y estructuran los espacios transnacionales.

En cuanto a la identidad, ésta es un elemento fundamental en la estructuración de un espacio (Klein, 2005), sobre todo en el marco de un espacio transnacional (Canales y Zlolniski, 2001). Es la identidad la que permite el reconocimiento mutuo entre los inmigrantes como partes integrantes de este espacio, principalmente en los casos de espacios discontinuos, donde se combina una identidad híbrida con respecto al territorio de origen y al territorio de residencia (Kniffki, 2013), lo que permite vivir y funcionar en la sociedad de acogida, sin asimilarse culturalmente y sin desligarse de la sociedad de origen.

Estos tres conceptos serán la guía para nuestro análisis. Son ellos los que utilizaremos para determinar si los mexicanos en Montreal forman parte de un espacio transnacional.

\subsection{Los pasos de la investigación empirica}

En nuestra investigación empírica, hemos tenido en cuenta variables económicas, políticas, socio-familiares y de identidad de los inmigrantes. La variable económica corresponde al conocimiento que poseen los inmigrantes acerca de las posibilidades económicas que ofrecen la ciudad de Montreal, la Provincia de Quebec y Canadá; la variable socio-familiar trata de los lazos entre los inmigrantes con su territorio de origen y con la sociedad en la que residen; la variable política se refiere a la participación de los inmigrantes en instancias políticas en México y en Canadá; y la variable de identidad corresponde al sentimiento de pertenencia de los inmigrantes mexicanos con respecto al territorio de origen y al medio montrealés. Estas variables se han desglosado en indicadores más finos, como se muestra en la tabla 1 . 


\section{Tabla 1 \\ Cuadro operativo de la investigación}

\begin{tabular}{|c|c|}
\hline Variable & Indicadores \\
\hline Económica & $\begin{array}{l}\text { Actividades económicas en el territorio de origen y en Montreal. } \\
\text { Emprendimientos de inmigrantes mexicanos en Montreal.Empren- } \\
\text { dimientos de inmigrantes mexicanos en México. } \\
\text { Importación y exportación de productos. } \\
\text { Comunidades que se benefician en México con remesas enviadas } \\
\text { por inmigrantes mexicanos. } \\
\text { Consumo de productos mexicanos por inmigrantes en Montreal. }\end{array}$ \\
\hline Socio-familiar & $\begin{array}{l}\text { Lazos de los inmigrantes con parientes y amigos en México. } \\
\text { Contactos con parientes y amigos.Desplazamientos hacia México. } \\
\text { Lazos con otros inmigrantes mexicanos en Montreal. } \\
\text { Participación en actividades de integración de inmigrantes en Mon- } \\
\text { treal. }\end{array}$ \\
\hline Política & $\begin{array}{l}\text { Participación en actividades políticas en México. } \\
\text { Participación en actividades políticas en Canadá. }\end{array}$ \\
\hline $\begin{array}{l}\text { Identidad y sentido } \\
\text { de pertenencia }\end{array}$ & $\begin{array}{l}\text { Participación en fiestas y celebraciones realizadas por instituciones } \\
\text { mexicanas en Montreal. } \\
\text { Vida cotidiana (hábitos religiosos, idioma, hábitos de cocina). } \\
\text { Apego al territorio de origen y e integración en Montreal. }\end{array}$ \\
\hline
\end{tabular}

Fuente: elaboración propia a partir de Faist (2000); Portes et al. (1999).

La búsqueda de información se llevó a cabo en tres etapas. Primero, se hizo un inventario de las instituciones y principales organizaciones de servicios destinados a los inmigrantes mexicanos en Montreal. Diversos materiales fueron obtenidos en diferentes organizaciones y asociaciones representativas de estos inmigrantes, los cuales fueron fichados y utilizados en diversas etapas de la investigación. Posteriormente, se realizaron entrevistas semi-estructuradas con representantes de instituciones y organizaciones entre la cuales estuvieron el consulado de México en Montreal, los centros de acogida de inmigrantes y el templo católico Notre-Dame-deGuadalupe. La información obtenida permitió establecer, en una tercera etapa, categorías específicas con respecto a la situación de los inmigrantes y su capacidad de emprendimiento: los empresarios, los profesionales en medios de trabajo y los refugiados. Las personas entrevistadas fueron seleccionadas con la ayuda del consulado de México en Montreal y de una organización de inmigrantes mexicanos. En total, se hicieron 20 entrevis$\operatorname{tas}^{3}$ (anexo 1).

La guía de entrevistas se elaboró a partir de los indicadores ya mencionados. Esta guía se dividió en dos partes. La primera parte indagó acerca

\footnotetext{
${ }^{3}$ Las entrevistas referidas en este documento son de fuentes fidedignas; no obstante, omitimos la identidad de nuestros informantes con el fin de procurar su seguridad. La información fue recabada de 2010 a 2012.
} 
de las características de base de los inmigrantes (lugar de origen, motivo de la inmigración, fecha de llegada a Montreal) y sobre su percepción de las redes constituidas por los mexicanos. La segunda parte indagó acerca de los indicadores correspondientes a las variables económica, socio-familiar, política y de identidad. Una sección adicional de la guía de entrevista se dirigió específicamente a los empresarios con el fin de obtener información más detallada acerca de sus actividades económicas. Las entrevistas fueron grabadas, transcritas y reportadas en una base de datos. El análisis se hizo a partir de las variables y los indicadores descritos. El conjunto del trabajo de campo se hizo entre los años 2010 y 2013.

\section{La comunidad mexicana}

Como se ha dicho, la emigración de mexicanos hacia Montreal es un fenómeno reciente. Montreal cuenta con una comunidad mexicana constituida por 17,630 personas, de ellas, 12,965 tienen el estatus de residente permanente o se han naturalizado como canadienses; 4660 no poseen el estatus de residentes permanentes, son personas con permiso de estudios o que han solicitado asilo y que están en espera de una decisión acerca de su residencia.

De los 12,925 inmigrantes con residencia permanente, 7030 han llegado a Canadá después del año 2006 y, por extensión, los que no poseen la residencia también están en Canadá desde hace pocos años. Esto significa que del total de los mexicanos asentados en Montreal, 66,3\% tiene menos de 10 años de residencia. No es extraño entonces que esta comunidad no muestre signos de madurez institucional y organizacional. En esta sección presentaremos un perfil general de estos inmigrantes. Primero, nos referiremos a los periodos de emigración y posteriormente describiremos sus características generales.

\subsection{Un flujo migratorio reciente}

Aunque algunas familias de origen mexicano se habían asentado en Montreal a partir de los años cuarenta (Burgueño, 2005), la presencia de inmigrantes mexicanos comienza a adquirir una cierta significación en los años setenta. Según nuestros entrevistados, la Exposición Universal realizada en Montreal en 1967, dio inicio a un primer periodo migratorio como consecuencia del establecimiento de relaciones personales establecidas por los mexicanos con canadienses durante este importante evento.

Un segundo periodo migratorio se sitúa entre los años 1980 y 2000. Durante este periodo, la migración de mexicanos aumentó, alcanzando 2320 nuevos inmigrantes. Los inmigrantes mexicanos de este periodo se 
caracterizaron por la presencia de profesionales solteros, que se instalaron en Montreal con el fin de hacer inversiones o para trabajar en el dominio de su formación académica. Durante esas dos décadas llegaron también los primeros refugiados políticos.

El tercer periodo migratorio se ubica a partir del año 2000. En éste llegaron 10,120 nuevos inmigrantes, de los cuales una parte importante son profesionales que eligieron Montreal para proseguir sus estudios superiores en las universidades de la ciudad. En este periodo se intensifica el flujo de los solicitantes de asilo, aspecto que generó dos realidades socioéconómicas: los inmigrantes profesionales que han ido adquiriendo una situación económica más o menos holgada y los asilados, quienes se encuentran en una situación más bien precaria.

\subsection{Causas de la emigración}

Diversos factores han influido en la salida de los inmigrantes mexicanos hacia Canadá. Si dejamos de lado el caso de los solicitantes de asilo, los factores más frecuentes han sido el desempleo y los bajos salarios. A esto se agrega el deseo de continuar una formación académica, principalmente en los ciclos de maestría y doctorado. La tabla 2 consigna las principales causas de emigración de los mexicanos instalados en Montreal en los tres periodos especificados en el numeral anterior.

\section{Tabla 2}

\section{Causas de la emigración de mexicanos hacia Montreal}

\begin{tabular}{|c|c|c|c|}
\hline Periodo & Años & Causas/motivos & Perfil de los inmigrantes \\
\hline Primero & $\begin{array}{l}\text { Decenio de } \\
1970\end{array}$ & $\begin{array}{l}\text { - Casamientos } \\
\text { - Inversiones }\end{array}$ & $\begin{array}{l}\text { - Sobre todo mujeres que } \\
\text { establecieron relaciones con } \\
\text { canadienses en la Exposición } \\
\text { Universal de } 1967 .\end{array}$ \\
\hline Segundo & $1980-2000$ & $\begin{array}{l}\text { - Falta de trabajo } \\
\text { - Crisis provocada por la } \\
\text { desvaluación del peso mexica- } \\
\text { no en } 1984 \\
\text { - Estudios de maestría y de } \\
\text { doctorado }\end{array}$ & $\begin{array}{l}\text { - Profesionales solteros. } \\
\text { - Primeros casos de solicitud } \\
\text { de asilo. }\end{array}$ \\
\hline Tercero & $\begin{array}{l}\text { A partir del } \\
\text { año } 2000\end{array}$ & $\begin{array}{l}\text { - Violencia (familiar, sexual, etc.) } \\
\text { - Falta de trabajo } \\
\text { - Bajos salarios } \\
\text { - Deseo de aumentar los ingresos } \\
\text { - Aspiración a un mejor nivel de } \\
\text { vida } \\
\text { - Estudios de maestría y de } \\
\text { doctorado }\end{array}$ & $\begin{array}{l}\text { - Diversos tipos. } \\
\text { - Aumento de las solicitaciones } \\
\text { de asilo. } \\
\text { - Profesionales. }\end{array}$ \\
\hline
\end{tabular}

Fuente: elaboración propia a partir de entrevistas (2010-2012). 


\subsection{Lugares de origen y lugares de instalación}

Los lugares de procedencia de los mexicanos instalados en Montreal se diversificaron después del 2000, en la medida en que el flujo migratorio se intensificaba. La ciudad de México y los estados de Puebla y Veracruz sobresalían como los lugares tradicionales de emigración. En la actualidad, los inmigrantes mexicanos establecidos en Montreal provienen de lugares diversos, entre los que destacan Durango, Guerrero, Hidalgo, Michoacán, Morelos, Nuevo León, Oaxaca, San Luis Potosí y Tamaulipas.

Con respecto a la instalación de los inmigrantes mexicanos en Montreal, su residencia es dispersa, en opinión de las personas entrevistadas. Este punto de vista coincide con la opinión de una institución de acogida a los inmigrantes. Los inmigrantes mexicanos se distribuyen en diversas zonas de Montreal, sin tener reagrupamientos geográficos específicos.

\subsection{El marco organizacional de los mexicanos en Montreal}

Un aspecto importante en el análisis de una comunidad es el de las organizaciones que la estructuran. Diversos tipos de organización tienden a jugar este papel en el caso de los inmigrantes mexicanos en Montreal.

\subsubsection{Organizaciones mexicanas en Montreal}

Existen dos organizaciones que ofrecen consejería a los mexicanos en su proceso de integración a la colectividad de Montreal. Estos dos organismos son Comunidad Mexicana de Quebec (Comexqc) y Casa Cafi. Comexqc surgió de una iniciativa de un grupo de mujeres, venidas en su mayoría en los años 1970. Inicialmente operó bajo el nombre de Asociación Mexicana de Canadá. Su finalidad es compartir información concerniente al acceso a los programas de ayuda gubernamental, a la adaptación al medio de acogida y a la educación de los niños. A partir del 2005, la asociación adquirió su nombre actual.

En cuanto a Casa Cafi, se trata de un centro de integración de los inmigrantes, creado en 1989 por mujeres mexicanas bajo el nombre de Centro de Desarrollo Social y Cultural Mexicano. Su finalidad era la de brindar información relacionada con la integración a la sociedad de acogida a los mexicanos que desconocían el inglés y el francés. Inicialmente, los beneficiarios de estos servicios eran los trabajadores agrícolas. Esta asociación desarrolla y promueve diversas actividades culturales y juega un rol de consejero a nivel de la integración de los inmigrantes en la sociedad de acogida. 
Además, en 2003 se creó en internet una red llamada Mexicanos inmigrantes y emigrados a Quebec, con el fin de hacer compartir la información sobre el proceso de inmigración y la obtención de la residencia permanente en Canadá. El primer encuentro del grupo se realizó en la ciudad de México en 2004, donde se reunieron veinte personas que comenzaron una fase de intercambio de información acerca del proceso de la futura instalación en Montreal.

Los temas giraban alrededor de comentarios sobre el costo de vida en Montreal, opciones de empleo, entre otros. La información compartida en los encuentros virtuales giraba alrededor de recomendaciones sobre el aprendizaje del francés, los recursos económicos necesarios para asegurar el sostenimiento durante los meses dedicados a la búsqueda de empleo e informaciones sobre la cultura quebequense específicamente.

Actualmente, la red actúa con el nombre "Aquí decidimos vivir", aunque comúnmente los inmigrantes se refieren a ella como Foro México-Quebec. Pertenecen a la red aspirantes a la migración y personas ya inmigradas. Los aspirantes, que esperan la visa en México, se reúnen mensualmente. En Montreal sus miembros se congregan regularmente en un restaurante mexicano; el contacto por internet les permite mantener los lazos entre los integrantes, poniendo de manifiesto la importancia de la comunicación virtual entre los inmigrantes. Al respecto, una líder del grupo comenta:

"[...] yo me vine, pero siguieron reuniéndose en México cada mes, cada mes [...] entonces compartimos información, reforzamos los lazos y yo digo: quiero cooperar, quiero que tu grupo sepa que aquí hay un lugar donde pueden llegar. Todo se hace vía internet, entonces realmente yo te puedo decir, el $80 \%$ de la funcionalidad de este grupo es vía internet, sin internet no podríamos llegar a este encuentro." (Entrevista personal, 26 de febrero de 2011).

Por otra parte, un grupo de profesionales de origen mexicano tuvo la iniciativa de crear en Montreal una asociación ligada a la red Comunidad de Egresados del Instituto Tecnológico de Monterrey (Exatec). Esta red tiene representaciones en varios países, su objetivo es crear puentes de información entre los egresados y facilitar intercambios académicos y de información. ${ }^{4}$ La seccional de Montreal fue creada en 2005 por iniciativa de cinco egresados y en 2011 ya contaba con 150 asociados. Sus acciones buscan la integración de los egresados, la realización de proyectos académicos y la realización de proyectos sociales. Esta última acción la realizan en colaboración con el consulado de México. Exatec ha establecido acuerdos con la Universidad de McGill y con el centro universitario HEC-

\footnotetext{
${ }^{4}$ En Canadá existen tres asociaciones: Exatec Toronto, Exatec Vancouver y Exatec Montreal.
} 
Montreal donde se ofrece un programa académico trilingüe en inglés, francés y español en el dominio de la administración.

Con respecto a la ayuda a los solicitantes de asilo, dos grupos han sido creados con este fin específico: el primero es Dignidad Migrante, un colectivo de trabajadores cuyo objetivo es denunciar las irregularidades cometidas por algunas agencias de empleo, en relación con las condiciones de trabajo y el pago de salarios. La iniciativa surgió en 2009, luego de una reunión a la que asistieron cuarenta personas. Lo anterior dio lugar a la creación de redes de solidaridad con el fin de sensibilizar a los trabajadores respecto a la defensa de sus derechos y darles el apoyo moral y material necesario, especialmente con aquellos a quienes les fue negada su estadía en Canadá.

El segundo grupo se llama Mexicanos Unidos por la Regularización (MUR). Este grupo surge a finales de 2011, con el fin de solicitar al gobierno de Canadá la puesta en marcha de un programa de regularización del estatus de los mexicanos establecidos en Quebec. El movimiento pretende llamar la atención con respecto a ciertos factores que afectan a su comunidad, como la explotación de los trabajadores — especialmente los indocumentados- el acceso a los servicios de salud y de educación y solicitar el cese de las deportaciones y las expulsiones de mexicanos del territorio canadiense. La tabla 3 muestra, a manera de resumen, las organizaciones de mexicanos encontradas en nuestro estudio, así como sus años de creación y actividades principales.

Un aspecto importante en la comunidad de inmigrantes mexicanos son los lugares de encuentro y de interrelación. Dos parroquias fueron identificadas por los entrevistados como sitios de encuentro entre los mexicanos: las parroquias Saint-Arsène y Notre-Dame-de-Guadalupe. También se mencionaron a algunos restaurantes, Casa Cafi y al consulado de México. Un responsable de una organización de inmigrantes nos explicó:

“[...] recientemente encontramos un sitio (restaurante para nuestros encuentros). Esta es la segunda vez que nos reunimos aquí y funciona, las personas comen lo que ellas quieren, o sea la comida mexicana, y uno se encuentra en un ambiente mexicano." (Entrevista personal, 26 de febrero de 2011).

\section{Iniciativas empresariales de los mexicanos en Montreal}

Entre las iniciativas empresariales de los mexicanos establecidos en Montreal, el sector de la restauración es el más importante. Más de una docena de restaurantes creados por mexicanos ha abierto sus puertas durante el último decenio, en su mayoría localizados alrededor de las calles Jean- 


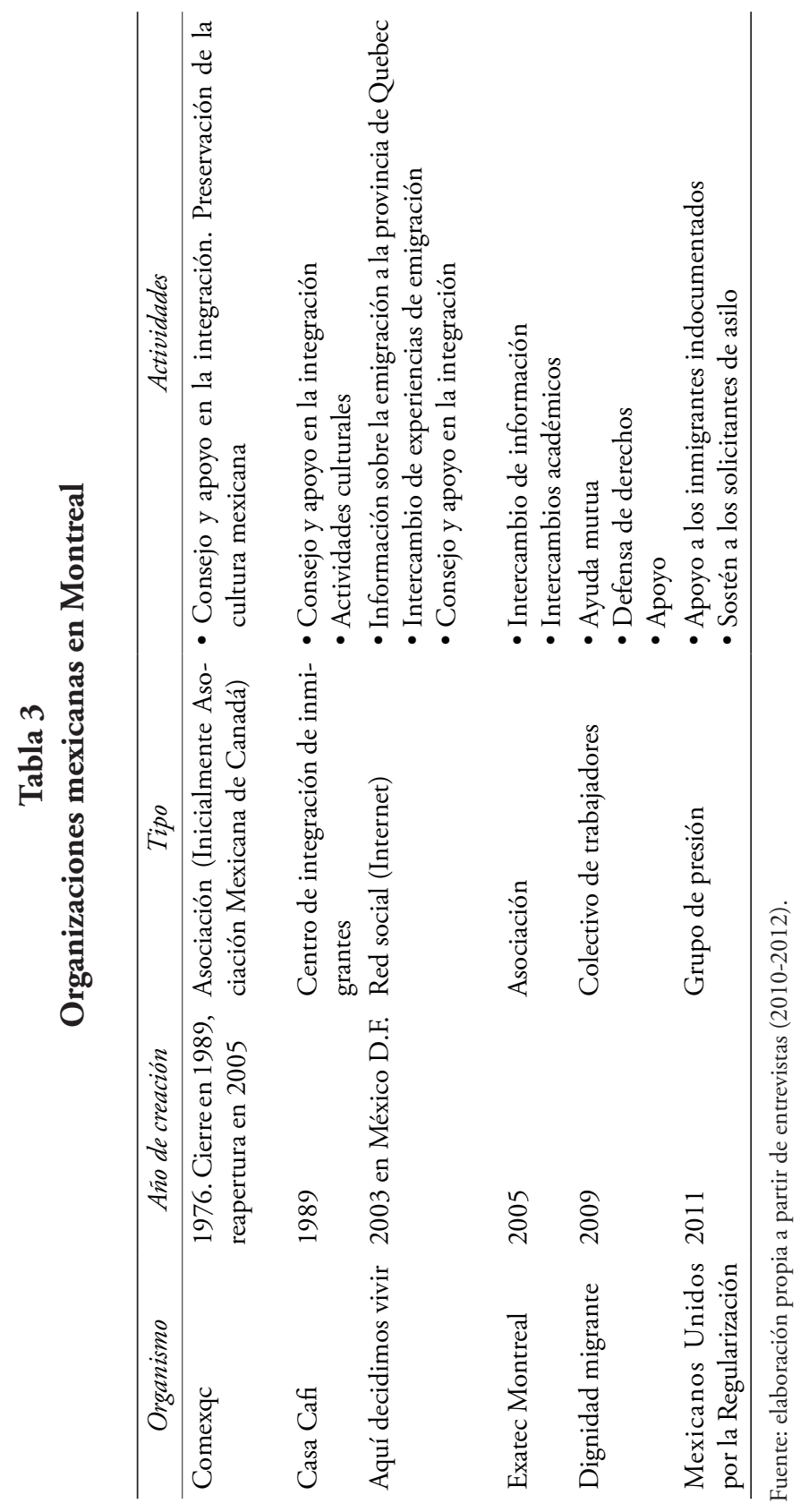


Talon y Saint-Laurent. Entre otras, Casa maya y La tortilla veloz, fabricantes de tortillas, y la Panadería mexicana, son iniciativas de inmigrantes mexicanos. Otras iniciativas son llevadas a cabo en los sectores del aseo, de las mudanzas, de la traducción, de las finanzas y de la música. Cabe mencionar la empresa Mariachi Figueroa, muy conocida, la cual reúne a tres generaciones de artistas de la misma familia, según los comentarios hechos por las personas entrevistadas.

Es importante destacar el impacto de las empresas importadoras de productos artesanales en las comunidades locales en México, las cuales tienen efectos sobre pequeñas comunidades de artesanos. Las más importantes son Importaciones San-Antonio, en el dominio de la artesanía, Orígenes México, dedicada a la importación de productos alimenticios y Tequilart, empresa que promueve alcoholes de origen mexicano en la provincia de Quebec. La primera comercializa artículos provenientes de siete estados mexicanos: Guanajuato, Michoacán, Puebla, Guerrero, Oaxaca, Querétaro y del Estado de México. También promueve artículos provenientes de comunidades indígenas, como Oaxaca, caracterizada por una gran variedad de bordados y artesanías.

En Puebla, Importaciones San-Antonio ha establecido contacto con los talleres La Colonia y San Juan de Aparicio, quienes practican el arte de la fabricación de la talavera ${ }^{5}$, así como la importación de telas en lana y cerámicas de Guanajuato. En cuanto a Orígenes México, ésta importa productos alimenticios, sobre todo innovadores producidos por pequeñas empresas, y que no se encuentran habitualmente en los supermercados. Tequilart, por su parte, importa el tequila proveniente de Jalisco, Nayarit, Guanajuato, Durango y Chihuahua. El mezcal proviene de Oaxaca y para el futuro proyectan importar vino del Estado de Baja California.

\section{La constitución de redes locales y globales}

Se preguntó a los entrevistados acerca de los lazos establecidos con otros inmigrantes de la misma nacionalidad y con su comunidad de origen. Abordaremos primero los lazos entre mexicanos en Montreal y luego los lazos establecidos con comunidades mexicanas en México.

\subsection{Relaciones con compatriotas en Montreal}

Dos factores emergen como determinantes de este tipo de relaciones: el medio de trabajo y el perfil socioeconómico de los inmigrantes. En lo que

\footnotetext{
${ }^{5}$ La talavera es un tipo de cerámica de origen árabe introducida en México durante la época colonial. Ver http://www.travelbymexico.com/puebla/atractivos/index3.php?nom=epuetalavera, 22 de julio del 2014.
} 
respecta al medio de trabajo, los profesionales y los empresarios consultados afirman tener relaciones múltiples, con colegas o interlocutores de diversos orígenes. No sienten la necesidad de establecer relaciones con otros mexicanos para ampliar sus redes sociales:

\begin{abstract}
"Mis amigos no son necesariamente mexicanos. Sí, yo tengo algunos, pero si lo pongo en una balanza, yo tengo más amigos extranjeros que mexicanos" (Entrevista personal, 25 de enero de 2011) "Yo tengo amigos mexicanos, pero me desenvuelvo más en una comunidad internacional”, agrega un representante de una organización (Entrevista personal, 13 de octubre de 2010). "Yo no tengo muchos amigos mexicanos", concluye un empresario (Entrevista personal, $26 \mathrm{de}$ enero 2011).
\end{abstract}

En cuanto a los inmigrantes en situación precaria, sobre todo los solicitantes de asilo, estos tampoco tienen lazos fuertes con compatriotas. Por una parte, sufren de una situación de aislamiento, y de otra, su estatus los lleva a desconfiar de su entorno, sobre todo en los días recientes a su llegada a Canadá. Los inmigrantes de esta categoría de entrevistados nos plantearon que en los primeros meses de su llegada a Montreal les era más fácil establecer relaciones con otros inmigrantes de diversos orígenes en una situación similar a la por ellos experimentada que con compatriotas mexicanos.

"Yo no tengo muchas oportunidades de salir. De hecho casi no salgo; yo salgo únicamente a la escuela de 'francización'. Ahorita yo me estoy relacionando más pero con las personas de aquí, con griegos, argentinos pero realmente con los mexicanos no" (Entrevista personal, 1 de febrero de 2011).

“[...] ahora empecé a implicarme más con la comunidad mexicana a raíz de que nos pusimos como meta este ańo (2011) lograr tener una amnistía (de los 'sin papeles') [...] pero cuando yo llegué ¿¿Sabes quiénes eran mi comunidad? Los chilenos. Yo me refugié con ellos, todos mis amigos eran chilenos" (Entrevista personal, 23 de febrero de 2011).

El origen étnico en este caso no parece ser un factor que lleve a establecer relaciones fuertes. Es más bien la condición socioeconómica y el proceso seguido en la migración los que juegan un papel preponderante. $\mathrm{Al}$ respecto, un entrevistado afirma:

"[...] al mexicano le gusta saber con quién se reúne, sí, somos un animal clasista, entonces como animal clasista no vas a querer reunirte en cualquier lugar con cualquier mexicano nada más por el hecho de ser mexicano [...], los residentes permanentes quieren reunirse con residentes permanentes porque saben que las 
personas que vinieron con el mismo sistema de migración tuvieron los mismos medios que ellos." (Entrevista personal, 26 de febrero de 2011).

\subsection{Lazos con los lugares de origen}

Los inmigrantes mexicanos entrevistados nos indican que los lazos con el lugar de origen se mantienen constantes, sobre todo con la familia. La mayoría de los entrevistados se comunica de manera frecuente a través de internet (Skype) y del teléfono. Los lazos con personas diferentes de la familia son menos duraderos. Un profesional nos dice:

\footnotetext{
"Para mí es esencial comunicarme con mi familia. Mis hermanos, mis padres, todos están allá; para mí es esencial llamarlos al menos una vez por semana" (Entrevista personal, 26 de enero de 2011). Un empresario agrega: "Tú estás aquí, pero tú no eres $100 \%$ de aquí; no olvidas tus raíces. Siempre estás en contacto con tus amigos o con tu familia” (Entrevista personal, 26 de enero de 2011).
}

Hay que decir, sin embargo, que en algunos casos, sobre todo en el caso de los refugiados, los inmigrantes deben suspender, al menos temporalmente, sus relaciones con sus parientes por razones de seguridad. Otros lo hacen por razones de orgullo en la medida que el trabajo que ocupan no corresponde al rango al cual estaban acostumbrados antes de emigrar. Un entrevistado que trabaja como obrero justifica su silencio con respecto a sus parientes y amigos de la manera siguiente:

"Creo que en el fondo a mí me cuesta aceptar mi trabajo [...] es una cuestión de orgullo que no esté capacitada para decirles ¿Qué crees que hago aquí? estoy en la fábrica. Como que me da pena” (Entrevista personal, 23 de febrero de 2011).

A pesar de los lazos familiares frecuentes, el envío de dinero de manera individual hacia la familia o a personas cercanas a esta no constituye una práctica generalizada entre las personas entrevistadas. Esto depende del tiempo que llevan como inmigrantes y de sus recursos. Los inmigrantes más recientes, es decir la gran mayoría, invierten sus ingresos en el proceso de inmigración y en su sostenimiento durante los primeros meses de su instalación antes de conseguir un empleo. En el caso de los demandantes de asilo, el grupo más desfavorecido, el trabajo precario y sus bajas remuneraciones solamente les permiten cubrir los gastos de subsistencia. Los envíos de dinero existen, pero son más bien puntuales y están reservados a los profesionales, los empresarios y los que tienen un empleo solvente.

En cuanto a iniciativas colectivas de apoyo a comunidades de origen, también son poco numerosas. La más importante es la iniciativa Riego Viejo, una iniciativa de ayuda por parte de inmigrantes empresarios a 
pequeños productores en México. Esta iniciativa se inscribe en el programa $3 x 1$, creado por el gobierno mexicano con el fin de generar y facilitar la ayuda de los mexicanos residentes en el extranjero hacia sus comunidades de origen. Así, por cada dólar invertido por los inmigrantes, los niveles de gobierno federal, provincial y municipal, invierten la misma cantidad. A falta de recursos financieros suficientes destinados al desarrollo de proyectos en las municipalidades, los inmigrantes pueden solicitar créditos a diferentes entidades gubernamentales como Sedesol (Secretaría de Desarrollo Social) o la Sagarpa (Secretaría de Agricultura, Ganadería, Desarrollo Rural, Pesca y Alimentación), con el fin de poner en práctica diversas iniciativas. En sus inicios, esta práctica fue llevada a cabo con inmigrantes establecidos en los Estados Unidos. Recientemente, esta práctica se ha puesto en marcha en Canadá.

El club Riego Viejo, creado en el 2009, fue la primera experiencia del programa 3x1, en Montreal. La idea fue concebida por una familia inmigrante procedente de San Alfonso, un pequeño pueblo de 100 habitantes, en su mayoría campesinos, perteneciente al municipio de Aquixtla situado en el norte del Estado de Puebla. El proyecto se inició con el cultivo de tomates en viveros, los cuales son comercializados en la Central de abastos de México.

Esta iniciativa da empleo a 15 trabajadores, una cifra considerable por el tamaño de la población de San Alfonso y además estratégica, debido a la conservación de las actividades agrícolas del lugar. En el momento este grupo planifica la obtención de recursos para la construcción de un centro de almacenamiento de tomates en alianza con la Financiera Rural, organismo de apoyo financiero a proyectos rurales en México.

En Montreal, el club está conformado por diez integrantes, y en San Alfonso por cuatro. El club fue inscrito en el consulado de México en Montreal en 2009. En San Alfonso, sus integrantes se organizaron en forma de asociación y están inscritos en la Sedesol. El club es financiado por los integrantes del club de Montreal, $\$ 1000$ son enviados mensual, bimensual o trimestralmente, a través de depósito en cuentas bancarias de los integrantes de San Alfonso, por medio de transferencias de dinero o a través de amigos.

Los afiliados de Montreal se encargan de ejecutar las diligencias de gestión y los miembros de San Alfonso de la ejecución del proyecto; "para el futuro se proyecta la puesta en marcha de un proyecto eco-turístico" (entrevista personal, 2 de febrero de 2012). 


\title{
6. La identidad de los inmigrantes mexicanos en Montreal
}

Existe consenso entre los entrevistados en que los inmigrantes del país azteca instalados en Montreal conservan su identidad mexicana, incluso en el caso de los asilados. Conservan sus tradiciones, su lengua y sus hábitos alimenticios. La amplia mayoría habla español en su casa y conservan sus hábitos de cocina. $\mathrm{Al}$ respecto, un entrevistado nos dice:

\begin{abstract}
"Yo compro un paquete de diez kilos de harina, la manteca me la regalan, entonces con los diez kilos de harina les hago mis tortillas de harina a mis hijos, les mando sus burritos en las mañanas, sus quesadillas, los frijoles, la salsita, pero la comida mexicana la tienen todos los días" (Entrevista personal, 1 de febrero de 2011).
\end{abstract}

\subsection{Hitos en la preservación de los hábitos y costumbres}

En esta materia, las celebraciones religiosas y patrióticas desempeñan un papel importante. Por ejemplo, la celebración del 15 de septiembre se realiza cada año en un parque importante de Montreal con asistencia promedio de 2500 mexicanos. Es el cónsul quien da el grito de la independencia. Para muchos, este es un momento emocionante, como lo afirma un inmigrante que lleva 32 ańos residiendo en Montreal:

\footnotetext{
"Yo, cuando el señor cónsul da el grito y cuando escucho el himno nacional [...] ándele, se me pone la piel de gallina a pesar de todos estos años y se me salen dos lagrimitas o tres, sí todavía. Y a mis hijos también, y ellos nacieron aquî" (Entrevista personal, 4 de febrero de 2011).
}

Y otro, que lleva 26 años, dice:

"El 15 de septiembre nosotros los mexicanos nos reunimos para celebrar la fiesta de nuestro país, para honrar nuestra bandera y nuestro himno nacional, para gritar Viva México, así no entendamos mucho qué pasó con la revolución y la independencia, eso no importa; lo importante es que somos mexicanos [...]" (Entrevista personal, 13 de octubre de 2010).

También hay que señalar la fiesta de la virgen de Guadalupe, la cual se realiza en la parroquia que lleva su nombre.

Estas celebraciones también influyen en la transferencia de las tradiciones mexicanas a los hijos, los cuales, en muchos casos, han nacido en Montreal:

"Cuando mis hijos nacieron, explica un empresario entrevistado, ahí fue cuando más yo me di cuenta que estaba muy alejado de todo lo que es la comunidad [mexicana], de todo lo que es mi cultura [...], entonces ahora que nacen mis 
hijas yo descubrí que para mí es muy importante heredarles mi cultura que es el único bien no tangible que tiene más valor. Además, yo les compro vestidos típicos mexicanos, las llevo a la celebración de la independencia mexicana y yo les compro música en español" (Entrevista personal, 28 de enero de 2011).

\subsection{La participación en la vida política}

En lo que respecta a la implicación de los inmigrantes mexicanos en la vida política, los entrevistados afirman que no participan en ningún grupo o partido ni en México ni en Canadá. ${ }^{6}$ Algunos participan en las elecciones en calidad de ciudadanos de ambos países. Sin embargo, en general, los entrevistados dicen tener poco interés tanto por la política local como por la política en México:

“[...] No me atrae mucho [la actualidad política], en México tampoco. Uno se entera de las noticias y uno comprende más o menos lo que pasa, pero no me implico, no reflexiono, no voy al detalle" (Entrevista personal, 8 de febrero de 2011).

\subsection{El desarrollo de una identidad hibrida: "ni de aqui, ni de allá..."}

A pesar de este apego a las costumbres mexicanas, la mayoría de los entrevistados viven su identidad en una cierta tensión. Algunos nos dicen que viven la sensación de no ser ni de México, ni de Canadá, "ni de aquí, ni de allá" (Entrevista personal, 4 de abril de 2011).

Un empresario afirma que no se siente ni canadiense, ni mexicano:

"[...] en mi interior yo puedo decirte que soy $100 \%$ mexicano, y al exterior, aquí, yo me siento canadiense porque yo participo, porque hago lo que la sociedad me demanda" (Entrevista personal, 26 de enero de 2011).

Y otro empresario agrega:

“[...] nosotros tenemos a veces ese conflicto, nos preguntamos ¿̨A qué lugar pertenezco? ¿Soy canadiense? ¿'Soy quebequense? Estamos entonces en una especie de conflicto" (Entrevista personal, 26 de enero de 2011).

Esto hace que muchos no consideren la idea de reinstalarse en México, a pesar del apego que tienen con respecto al terruño mexicano y a sus tradiciones, como lo muestran las citaciones siguientes:

${ }^{6}$ Esta información hay que tomarla con precaución. Algunos entrevistados manifestaban un cierto recelo y una cierta desconfianza al responder a esta pregunta. 
"A veces yo digo: yo quisiera estar más tiempo [en México] [...] pero me doy cuenta que ya no puedo integrarme completamente a lo que fue [...]" (Entrevista personal, 2 de febrero de 2011).

"Es muy difícil, muy difícil porque cuando yo voy a México, yo me siento extranjero [...] Yo voy a ser mexicano siempre, seguro, pero yo ya me integré aquí [...]" (Entrevista personal, 4 de abril de 2011).

Cabe preguntarse en qué medida esta identidad compartida, que se basa en la adhesión a un pasado mexicano y a la vida actual en la ciudad de Montreal, influye en la integración de los inmigrantes mexicanos en la sociedad montrealesa. Es lo que trataremos en la sección siguiente.

\section{Integración de los mexicanos en la colectividad montrealesa}

Partamos del hecho que tal integración no ha tenido lugar. Lo anterior está motivado, por un lado, por las dificultades y las trabas en términos de reconocimiento profesional, y por otro lado, por el apego que los mexicanos sienten con respecto a su país de origen. Se les pidió a los entrevistados que se refirieran a su nivel de integración. Todos afirman que una integración total es imposible. Uno de los que se autorreconoce como más integrado, afirma:

"Yo trabajo por esto [lograr la integración], trabajo a todos los niveles, perfeccionando la lengua, conociendo la cultura, comprendiendo al pueblo quebequense, pero conservo mi identidad" (Entrevista personal, 26 de enero de 2011).

Y uno de los que se consideran menos integrados dice:

"Puedes conocer la lengua, tener un trabajo, seguir estudios superiores, pero siempre habrán otros que no cesarán jamás de considerarte como un extranjero" (Entrevista personal, 23 de febrero de 2011).

Nuestros entrevistados subrayan las dificultades para integrarse socialmente en la colectividad de Montreal. Hay consenso acerca de la importancia del dominio de la lengua francesa, lo que causa ciertas dificultades:

"[...] es difícil [la integración], sobre todo cuando uno no habla la lengua." (Entrevista personal, 8 de febrero de 2011). "Sí, yo me he integrado un poco, pero me falta el aspecto de la lengua, eso me inhibe mucho" (Entrevista personal, 1 de febrero de 2011).

Algunos entrevistados señalan que la integración es difícil a causa de que la información, dada por las autoridades canadienses y por diversas agencias en el territorio de origen, no corresponde con la realidad que se 
encuentra en la sociedad de acogida. Esto es particularmente importante en lo que respecta al reconocimiento de los estudios y de los títulos profesionales.

\section{Los mexicanos en Montreal: una comunidad en gestación}

Según la apreciación de los entrevistados, los mexicanos en Montreal no constituyen aún una comunidad organizada. Para la mayoría, las relaciones y las redes entre ellos se estructuran en función del periodo migratorio y del estatus social y jurídico (tabla 4). Los inmigrantes instalados entre 1970 y 1980 tienen pocas relaciones con los que llegaron en 2000. Un empresario expresa lo siguiente:

\footnotetext{
"Yo creo que los mexicanos son solidarios, pero no están organizados, hay varios grupos aislados sin comunicación entre ellos. Falta mucha organización" (Entrevista personal, 13 de octubre de 2011).
}

Un hecho interesante de destacar, es que si los empresarios muestran una tendencia a la asociación entre mexicanos, los refugiados establecen redes con personas de otras nacionalidades. Sin embargo, los entrevistados manifiestan que existe un potencial de solidaridad, especialmente en momentos de catástrofes naturales como la ocurrida en el sismo de 1985. $\mathrm{Al}$ respecto, una entrevistada comenta:

\footnotetext{
"[...] cuando el temblor nosotros creamos un comité de ayuda con gente de aquí. Logramos reunir 340,000 dólares que fueron enviados a México a través de Desarrollo y Paz" (Entrevista personal, 4 de febrero de 2011).
}

\section{Conclusiones}

La falta de solidez en la comunidad mexicana de Montreal no es sorprendente. Existe un potencial de solidaridad entre los inmigrantes mexicanos que los conduce a movilizarse y poner en práctica iniciativas solidarias con respecto a sus compatriotas en esta ciudad. Sin embargo, hasta el momento no se puede hablar de una efectiva comunidad transnacional, teniendo en cuenta el bajo nivel de desarrollo de sus lazos con respecto a sus comunidades de origen y la incipiente organización institucional en la metrópolis quebequense.

Los objetivos propuestos por este estudio fueron: la exploración de las prácticas económicas, sociales, políticas y de identidad de los inmigrantes de origen mexicano instalados en Montreal, y el estudio de las formas de organización de esta comunidad, así como su aporte al desarrollo de las comunidades de origen en México. 


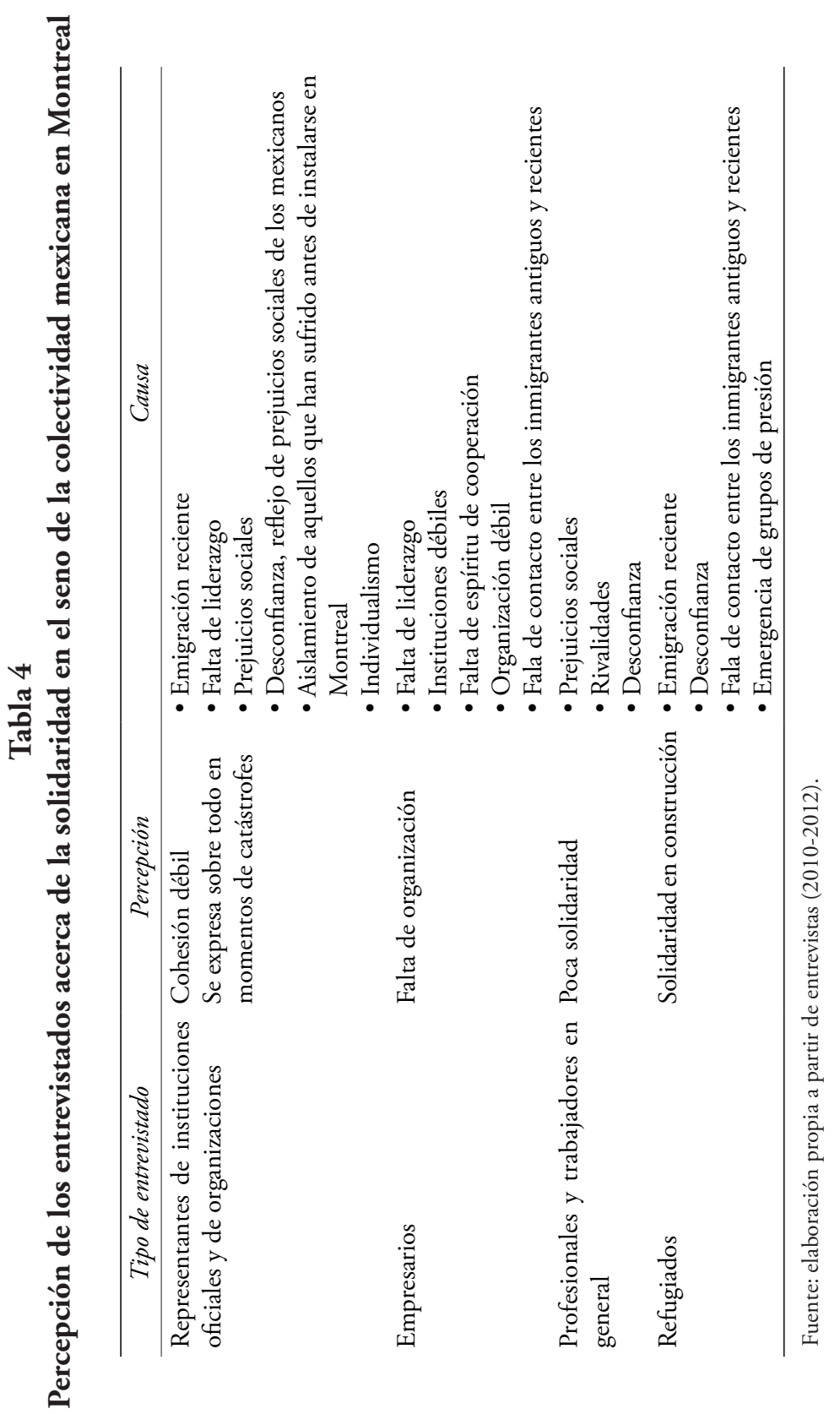


Con respecto a las prácticas económicas desarrolladas por los mexicanos, éstas corresponden principalmente al sector de la restauración. En otras actividades se inscriben en la limpieza, las mudanzas, la traducción, las finanzas y en el sector artístico. Respecto a la comercialización de productos de origen mexicano, con el tiempo esta actividad ha venido ganando importancia, aunque hasta el momento ha estado en manos de empresarios de otros orígenes diferentes al mexicano y gran parte de estos productos no son fabricados en México. Texas y Chicago en Estados Unidos y Ontario en Canadá son centros de producción y comercialización de estos productos, por lo cual este ramo de la economía es poco desarrollada directamente por los mexicanos.

Con respecto al desempeño de los mexicanos en Montreal, ellos se encuentran en diversos sectores de la economía: las fábricas, el comercio al detalle, el alojamiento y la restauración. Los profesionales se encuentran en el sector de las ventas, finanzas, negocios y a nivel de la administración. Las entrevistas evidenciaron la presencia de mexicanos en las fábricas, la construcción y en fincas. Estas personas poseen diferentes niveles de educación; algunos profesionales con diploma de maestría en México, quienes prefieren realizar estos trabajos antes que retornar a su país, debido a la inestabilidad, el desempleo y los bajos salarios.

En cuanto al nivel de integración de los mexicanos en la provincia de Quebec y en Montreal —según las personas entrevistadas- aunque algunos la consideran fuerte, la integración total no existe. El bajo nivel de conocimiento de la lengua, sobre todo del francés, es una barrera para insertarse en el mercado del trabajo. En relación con los solicitantes de asilo, las largas esperas por las respuestas de parte del gobierno canadiense no les permite proseguir sus estudios o acceder a un empleo estable, por lo tanto este grupo se ocupa en empleos precarios y son las personas menos integradas a la sociedad de acogida.

Las acciones y gestos de solidaridad económica de los mexicanos instalados en Montreal con sus comunidades en las localidades de origen son frecuentes, aunque aún embrionarios. Sin embargo, algunas organizaciones han creado redes con su comunidad de origen; es el caso del Club Riego Viejo, el cual es gerenciado por inmigrantes provenientes de San Alfonso (Estado de Puebla). Esta organización, inscrita en el programa $3 \times 1$ del gobierno mexicano, ha logrado poner en contacto a inmigrantes establecidos en Montreal, con su comunidad de origen en México, conformando una práctica transnacional.

La migración mexicana a Montreal se considera reciente, por lo tanto se halla en fase de construcción de un nuevo espacio de relaciones, por consiguiente, los mexicanos instalados en Montreal pueden llegar a tener un mayor impacto sobre sus comunidades en los lugares de origen en la 
medida en que ellos sean capaces de unir esfuerzos y de borrar diferencias sociales. Hasta el momento, la mayoría de las iniciativas existentes movilizan a personas con objetivos concretos que responden a situaciones particulares y no se sustentan en la identidad mexicana propiamente dicha.

Finalmente, se constató que el sentimiento de identidad híbrida o compartida de los inmigrantes entre los lugares de acogida y de origen, una de las características esenciales del transnacionalismo, está presente entre los inmigrantes mexicanos que se encuentra viviendo en Montreal. Existe un sentimiento de pertenencia a Montreal, pero se siguen considerando mexicanos: es un sentimiento de no ser "ni de aquí ni de allá".

\section{Anexo 1 \\ Lista de entrevistados}

\begin{tabular}{|c|c|c|c|}
\hline Grupo & Núm. & Persona / institución & Fecha \\
\hline Instituciones del & 1 & Consulado General de México en Montreal & $21-7-2010$ \\
\hline \multirow{2}{*}{$\begin{array}{l}\text { Gobierno Mexicano } \\
\text { en Montreal }\end{array}$} & 5 & Proméxico (Montreal) & $25-1-2011$ \\
\hline & 15 & TechBa. Technology Business Accelerator & $11-2-2011$ \\
\hline \multirow[t]{7}{*}{ Organizaciones } & 2 & $\begin{array}{l}\text { ALAC. Association latino-américaine de } \\
\text { Côte-des-Neiges }\end{array}$ & $27-7-2010$ \\
\hline & 4 & Église Notre-Dame-de-Guadalupe & 03-11-2010 \\
\hline & 11 & $\begin{array}{l}\text { Chaire d'études sur le Mexique contempo- } \\
\text { rain, Université de Montréal }\end{array}$ & $02-2-2011$ \\
\hline & 3 & $\begin{array}{l}\text { Casa Cafi. Centre d'aide aux familles in- } \\
\text { migrantes }\end{array}$ & $13-10-2010$ \\
\hline & 12 & $\begin{array}{l}\text { Comexqc. Communauté mexicaine du } \\
\text { Québec }\end{array}$ & $04-2-2011$ \\
\hline & 19 & Aquí decidimos vivir & $26-2-2011$ \\
\hline & 20 & Club Riego Viejo & $02-2-2012$ \\
\hline \multirow[t]{4}{*}{ Empresarios } & 7 & Empresario 1. Restaurante & 26-1-2011 \\
\hline & 9 & Empresario 2. Importación de licores & 28-1-2011 \\
\hline & 14 & $\begin{array}{l}\text { Empresario 3. Importación de productos } \\
\text { alimenticios }\end{array}$ & $08-2-2011$ \\
\hline & 17 & Empresario 4. Importación de artesanías & $22-2-2011$ \\
\hline \multirow[t]{3}{*}{ Profesionales } & 6 & $\begin{array}{l}\text { Exatec. Asociación de Exalumnos del } \\
\text { Instituto Tecnológico de Monterrey }\end{array}$ & $31-1-2011$ \\
\hline & 8 & Profesional 1 (Sector turismo) & $26-1-2011$ \\
\hline & 16 & Professional 2 (Profesor) & $12-2-2011$ \\
\hline \multirow[t]{3}{*}{ Refugiados } & 10 & Refugiado 1 & $01-2-2011$ \\
\hline & 18 & Refugiado 2 & 23-2-2011 \\
\hline & 13 & Dignidad Migrante (defensa de refugiados) & $04-2-2011$ \\
\hline
\end{tabular}




\section{Fuentes consultadas}

Ávila-Molero, Javier (2015), "Repensando la etnicidad y el transnacionalismo desde el análisis de redes personales", REDES. Revista hispana para el análisis de redes sociales, 26 (2), Universidad Autónoma de Barcelona y Universidad de Sevilla, <http://revistes. uab.cat/redes/article/view/v26-n2-avila/585-pdf-es $>, 23$ de diciembre de 2015.

Aranzazu, Mauricio (2013), "Pratiques économiques et socio-culturelles des mexicains à montréal: une étude exploratoire de l'espace transnational Mexique-Montréal", tesis de maestría en Geografía, Université du Québec à Montréal, Montréal.

Badie, Bertrand (1995), La fin des territoires, Fayard, Paris.

Benko, Georges y Alain Lipietz (eds.) (1992), Les régions qui gagnent districts et réseaux: les nouveaux paradigmes de la géographie économique, PUF, Paris.

Blanco, Cristina (2007), “Transnacionalismo. Emergencia y fundamentos de una nueva perspectiva migratoria", Papers Revista de Sociología, 85, Universidad Autónoma de Barcelona, Barcelona, pp. 13-29, <http://www.raco.cat/index.php/Papers/article/view/74158/ $94201>, 1$ de agosto de 2014.

Bruneau, Michel (2004), Diasporas et espaces transnationaux, Anthropos, Paris.

Bruneau, Michel (2009), "Communauté transnationale", Hypergeo, $<$ http://www.hypergeo.eu/spip.php?article143>, 18 de diciembre 2010.

Burgueño, Karla (2005), “La migración mexicana en Québec”, Revista Mexicana de Estudios Canadienses, núm. 9, Asociación mexicana de estudios sobre Canadá, Culiacán, pp. 95-113. http://redalyc. uaemex.mx/src/inicio/ArtPdfRed.jsp?iCve=73900906. $11 \mathrm{de}$ febrero de 2010.

Cabezas, Rhina Marlene (2012), "Transnacionalismo y modelos de codesarrollo: impacto en el desarrollo local de las comunidades de origen. Estudio de caso: El Salvador y Colombia”, tesis doctoral, 
Facultad de Ciencias Políticas y Sociología, Universidad Complutense de Madrid, Madrid.

Canales, Alejandro y Christian Zlolniski (2001), "Comunidades transnacionales y migración en la era de la globalización”, Revista Notas de Población, núm. 73, CEPAL-CELADE, Santiago de Chile, <file:///C:/Users/carlos/Downloads/NP01073_es\%20(1). pdf>, 31 de julio 2014.

Castells, Manuel (2001), La galaxie Internet, Faiyard, Paris.

Castells, Manuel (ed.) (2004), The network society, Edward Elgar, Londres.

Delgado, Raúl y Oscar Mañán (2005), “Migración México-Estados Unidos e integración económica", Política y Cultura, núm. 23, Universidad Autónoma Metropolitana, México, pp. 9-23.

Enríquez-Rosas Rocío (2000), "Redes sociales y pobreza: mitos y realidades", Revista de estudios de género. La Ventana, núm. 11, Universidad de Guadalajara, Guadalajara, México, pp. 36-72.

Faist, Thomas (2013), “Ahora todos somos transnacionales: relevancia de la transnacionalidad para comprender las inequidades sociales", Migración y Desarrollo, 11 (20), Red Internacional de Migración y Desarrollo, Zacatecas, México, pp. 67-105, <http:// www.redalyc.org/articulo.oa?id=66028343004>, 20 de diciembre de 2015 .

Faist, Thomas (2000), "Transnationalization in international migration: implications for the study of citizenship and culture", Ethnie and Racial Studies, 23 (2), Taylor and Francis Online, pp. 189-222, <http://hevra.haifa.ac.il/-socnecturers/smooha!files/180 l.pdf>, 18 de diciembre de 2011.

Falciglia, Sophie (2013), "Les travailleurs agricoles mexicains saisonniers au Québec: le contrat de travail comme facteur d'exclusion et d'inégalités", tesis de maestría en Geografía, Université du Québec à Montréal, Montréal.

Faret, Laurent (2003), Les territoires de la mobilité. Migration et communautés transnationales entre le Mexique et les Etats-Unis, CNRS Éditions, Paris. 
García de La Torre, Consuelo (2011), "Initiatives sociales au Mexique, le cas de Construmex", conferencia dictada en el marco del Seminario Iniciativas locales y modelos de gobernanza: miradas cruzadas, Centre de recherche sur les innovations sociales CRISES, Montréal, 3 de noviembre de 2011.

Garduño, Everardo (2003), “Antropología de la frontera, la migración y los procesos transnacionales", Frontera Norte, 15 (30), El Colegio de la Frontera Norte, Tijuana, pp. 65-89.

Glick-Schiller, Nina, Linda Basch y Christina Blanc-Szanton (1992), "Towards a definition of transnationalism. Introductory remarks and research questions", en Nina Glick-Schiller, Lina Basch y Christina Blanc-Szanton (eds.) Towards a transnational perspective on migration: race, class, ethnicity and nationalism reconsidered, New York Academy of Sciences, New York, pp. 1-24.

Hiernaux-Nicolas, Daniel (1999), Los senderos del cambio, Plaza y Valdés Editores, México.

Huang, Ping (2013), "La solidarité numérique: réponse locale à l'exclusion et redéfinition des stratégies de développement en matière de TIC", tesis de doctorado en Estudios Urbanos, Université du Québec à Montréal, Montréal.

Kastoryano, Riva (2000), "Immigration, communautés transnationales et citoyennete”, Revue Internationale des Sciences Sociales, núm. 165, Éditions érès, Toulouse, pp. 353-359.

Klein, Juan Luis (2016), "La mondialisation. De l'État-nation à l'espace monde", en Juan-Luis Klein y Frédéric Lasserre (dirs.), Le monde dans tous ses États. Une aproche géographique, Presses de l'Université du Québec, Québec, pp. 51-74.

Klein, Juan Luis (2014), "Innovation sociale et développement territorial", en Juan-Luis Klein, Jean-Louis Laville y Frank Moulaert (eds.), L'innovation sociale, Érès, Toulouse, pp.115-139

Klein, Juan Luis (2006), “Geografía y desarrollo local”, en Daniel Hiernaux-Nicolas y Alicia Lindon (eds.), Tratado de Geografía Humana, Anthropos, Barcelona, pp. 303-319. 
Klein, Juan Luis (2005), “Iniciativa local y desarrollo”, EURE, 21 (94), Pontificia Universidad Católica de Chile, Santiago de Chile, pp. 25-39

Klein, Juan Luis (1997), "L'espace local à l'heure de la globalisation: la part de la mobilisation sociale", Cahiers de géographie du Québec, 41 (114), Université Laval, Quebec, pp. 367-377.

Kniffki, Johannes (2013), “Transnacionalidad y comunidad: un enfoque construccionista y discursivo", Espacios transnacionales, núm. 1, Red Latinoamericana-Europea de Trabajo Comunitario Transnacional, <http://www.espaciostransnacionales.org/>, 28 de diciembre de 2015 .

Lacroix, Thomas (2003), "Espace transnational et territoire. Les réseaux marocains du développement", tesis de doctorado, Departamento de geografía, Université de Poitiers, Poitiers.

Lambert, Dominique (2015), "Établissement d'une communauté chinoise à Brossard en banlieue montréalaise: le rôle des agents immobiliers", tesis de maestría en geografía, Université du Québec à Montréal, Montréal.

Martiniello, Marco (2007), “Transnationalisme et immigration”, Écarts d'identité, 2 (111), Université de Liège, Liège, pp. 76-79.

Moctezuma, Miguel (2008), "Transnacionalidad y transnacionalismo", Papeles de Población, 57 (14), Universidad Autónoma del Estado de México, Toluca, pp. 39-64, <http://www.redalyc.org/articulo. da? $\mathrm{id}=11205702>, 23$ de diciembre de 2015 .

Moctezuma, Miguel (2002), "Los inmigrantes mexicanos en los Estados Unidos y la inversión productiva en México", Migraciones Internacionales, 1 (002) Colegio de la Frontera Norte, Tijuana, pp. 149-162.

Narváez-Gutiérrez, Juan Carlos (2007), Ruta transnacional: a San Salvador por los Ángeles. Espacio de interacción juvenil en un contexto migratorio, Miguel Ángel Porrua-UAZ-Instituto Mexicano de la Juventud, México. 
Pedraza, Joel y Edith Cortés (2012), “'El myespace lo trajeron del norte.' Redes sociales y migración: formación de comunidades transnacionales virtuales", Virtualis, 3 (6), Instituto Tecnológico y de Estudios Superiores de Monterrey, <http://aplicaciones.ccm. itesm.mx/virtualis>, 26 de diciembre de 2015.

Portes, Alejandro (2004), El desarrollo futuro de América Latina. Neoliberalismo, clases sociales y transnacionalismo, ILSA, Bogotá, Colombia, <http://ilsa.org.co:81/biblioteca/dwnlds/eclvs/eclvs07/Eclvs07-06.pdf>, 6 de diciembre de 2011.

Roldán, Ana Isabel (2009), "Migración juvenil en Latinoamérica y el Caribe", Organización de los Estados Americanos-Young Americas Business Trust, <http://scm.oas.org/doc_public/SPANISH/ HIST_09/CP23079S04.doc>, 25 de enero 2010.

Rottenbenger-Kwok, Kim (2007), "Léconomie transnationale des immigrants chinois en Autriche”, en Laurence Roulleau-Berger (ed.), Nouvelles migrations chinoises, Université de Vienne, Vienne, pp. 141-155.

Sassen, Saskia (2007), A sociology of globalization, WW Norton, New York.

Smith, Michel y Luis Guarnizo (eds.) (1998), Transnationalism from below. Transaction Publishers, New Brunswick.

Statistique Canada (2011), Enquête nationale auprès des ménages de 2011: Tableaux de données, <http://www12.statcan.ca/>, 21 de julio de 2014.

Swyngedouw, Erik (1997), "Neither global nor local: Glocalization and the politics of scale", en Kevin R. Cox (ed.), Spaces of globalization, The Guilford Press, New York, pp. 137-166.

Recibido: 13 de abril de 2015. Corregido: 17 de diciembre de 2015 . Aceptado: 3 de febrero de 2016. 
Juan Luis Klein. Chileno-Canadiense. Ph.D en geografía por la Universidad Laval; es profesor titular del departamento de geografía y director del Centro de Investigación sobre las Innovaciones Sociales (Centre de Recherche sur les Innovations Sociales). Entre sus publicaciones destacan, en coautoría: (ed.) L'innovation locale à l'épreuve du global: un défi pour les acteurs, Presses de l'Université du Québec, Québec (2016); Linnovation sociale, Érès, Toulouse (2014); Vers une nouvelle géographie économique, Presses de l’Université du Québec, Québec (2014).

Mauricio Aranzazu. Colombiano-Canadiense. Magister en geografía, Université du Québec à Montréal. Actualmente trabaja para la Dirección General de Ordenamiento Ambiental Territorial del Ministerio de Ambiente y Desarrollo Sostenible de Colombia. Anteriormente fue profesor del Departamento de Historia y Geografía de la Universidad de Caldas en Manizales, Colombia, del 2002 al 2008, y asistente de investigación en el Centro de Investigación sobre las Innovaciones Sociales (Centre de recherche sur les innovations sociales. Entre sus publicaciones destacan: "Pratiques économiques et socio-culturelles des Mexicains à Montréal: une étude exploratoire de l'espace transnational Mexique-Montréal", tesis de maestría en geografía, Universidad de Québec en Montréal, Montréal (2013). 
